\title{
Case control study: magnetic resonance spectroscopy of brain in HIV infected patients
}

\author{
Devender Bairwa', Virendra Kumar², Surabhi Vyas ${ }^{3}$, Bimal Kumar Das ${ }^{4}$, Achal Kumar Srivastava ${ }^{5}$, \\ Ravinder M. Pandey ${ }^{6}$, Surendra K. Sharma ${ }^{1}$, Naranamangalam R. Jagannathan ${ }^{2}$ and Sanjeev Sinha ${ }^{1 *}$
}

\begin{abstract}
Background: In vivo proton magnetic resonance spectroscopy ('H-MRS) studies on brain in HIV infected patients have shown significant alteration in neuro-biochemicals.

Methods: In this study, we measured the neuro-biochemical metabolites from the left frontal white matter (FWM) and left basal ganglia (BG) caudate head nucleus in 71 subjects that include 30 healthy controls, 20 asymptomatic HIV and 21 HIV patients with CNS lesion. Proton MR spectra were acquired at 3 T MRI system and the concentration (institutional units) of tNAA (N-acetylaspartate, NAA + N-acetylaspartylglutamate, NAAG), $\mathrm{tCr}$ (Creatine, $\mathrm{Cr}+$ phosphocreatine, $\mathrm{PCr}$ ), choline containing compounds (tCho), glutamate + glutamine (G|x) and lipid and macromolecules at 0.9 ppm were determined using LC Model.

Results: In BG, the concentration of tNAA $(6.71 \pm 0.64)$ was decreased and in FWM, the concentration of GIx (20.4 \pm 7.8$), \mathrm{tCr}(9.14 \pm 3.04)$ and lipid and macromolecules at $0.9 \mathrm{ppm}(8.69 \pm 2.96)$ were increased in HIV patients with CNS lesion. In healthy controls, the concentration of tNAA in BG was $7.31 \pm 0.47$ and concentration of GIX, $\mathrm{tCr}$ and lipid and macromolecules in FWM were $15.0 \pm 6.06,6.95 \pm 2.56,5.59 \pm 1.56$, respectively.

Conclusion: Reduced tNAA in BG suggests neuronal loss in HIV patients with CNS lesion while increased GIx in FWM may suggest excito-toxicity. In addition, increased levels of tCr in FWM of HIV patients were observed. The study indicates region specific metabolic changes in tNAA, tCr and GIx in brain of HIV infected patients.
\end{abstract}

Keywords: Magnetic resonance spectroscopy, MRS, HIV, AIDS, Glutamate

\section{Background}

Human immunodeficiency virus (HIV) continues to be a major global public health issue. Approximately 36.9 [34.3-41.4] million people were living with HIV in 2014 whereas 2.0 [1.9-2.2] million people died of HIV related illnesses in 2014 and more than $95 \%$ of all HIV-infected people now live in developing world [1]. India ranks third with the estimated number of people living with HIV/AIDS is approximately 2.089 million (2012) with an estimated adult (15-49 age group) HIV prevalence of $0.27 \%$ in 2011 [2].

\footnotetext{
* Correspondence: drsanjeevsinha@gmail.com

${ }^{1}$ Department of Medicine, All India Institute of Medical Sciences, Ansari

Nagar, New Delhi 110029, India

Full list of author information is available at the end of the article
}

Central nervous system (CNS) involvement in HIV can occur both early as well as late. Early involvement is characterized by impaired abstracting ability, learning difficulties and slow speed of information processing. Late involvement of CNS can be either by neoplasms or opportunistic infections [3].

Opportunistic infection includes toxoplasmosis, cryptococcosis, progressive multifocal leucoencephalopathy and tuberculosis. Neoplasms include primary CNS lymphoma, Kaposi's sarcoma and result of HIV-1 infection includes aseptic meningitis, HIV-associated neurocognitive impairment, including HIV encephalopathy/ AIDS dementia complex [4].

MRS studies of brain have reported change in metabolite levels in HIV patients. Many studies have reported changes in $\mathrm{N}$-acetylasparatate (NAA) and creatine $(\mathrm{Cr})$ 
levels in different regions of brain, however, the results reported across these studies are not consistent and sometimes contradictory [5-8]. Chong et al. [5] reported that there is significant reduction in the mean NAA to choline (Cho) ratio and $\mathrm{NAA} / \mathrm{Cr}$ and an increase in $\mathrm{Cho} / \mathrm{Cr}$ was observed in HIV patients with immunosupressed state and neurologic signs. Suwanwelaa et al. [7] showed a statistically significant reduction in NAA/Cr and NAA/Cho in centrum semiovale and thalamic areas with no statistically significant difference in $\mathrm{Cho} / \mathrm{Cr}$ and $\mathrm{mI} / \mathrm{Cr}$ in both the regions. The difference of NAA/Cr was more pronounced in white matter than in gray matter. In addition, HIV infection has been linked with neuro-cognitive impairment which has been shown to result in increased excite-toxicity of glutamate $[9,10]$. In this context, glutamate concentration in brain has been studied and found to be significantly increased in CSF, plasma and brain tissues by using biochemical methods in patients with HIV infection [9]. In the present study, we have quantified changes in brain neuro-biochemical levels in patients with HIV infection at 3.0 Tesla using in vivo single voxel proton magnetic resonance spectroscopy $\left({ }^{1} \mathrm{H}\right.$ MRS).

\section{Methods}

\section{Participants}

A total of 71 subjects were recruited under this study from March 2014 to October 2015 including 30 healthy subjects (Group 1), 20 HIV asymptomatic patients (Group 2) and 21 HIV patients with CNS lesions (Group 3). Institute Ethics Committee approved the study and written informed consent was obtained from all the participants in the study. In case of patients with altered sensorium, consent was obtained from their relatives accompanying them to the hospital. Healthy subjects were with no history of high risk behavior, any prolonged medical or surgical illness.

\section{Physical examination and neurological evaluation}

All the subjects underwent general physical examination and detailed clinical neurological examination. Subjects in Group 2 included sero-positive HIV patients with CD4 count $<500 / \mathrm{ul}$ and on anti-retroviral therapy (ART), with normal neurological, neuropsychological examination and no apparent CNS involvement and were screened with the help of international HIV dementia scale for any possible subclinical HIV associated neuro-degeneration (HAND). Group 3 included HIV patient, with CNS involvement apparent on imaging (MR, CT, PET), blood investigations or CSF study. Socioeconomic status was derived by using Modified Kuppuswamy Scale last modified in 2012 [11]. For all participants baseline respiratory rate, heart rate, blood pressure and temperature were recorded.

\section{Biochemical investigations}

HIV status was confirmed for all subjects using ELISA for HIV1 and HIV2 infection. In case of patients in Group 2 and Group 3, most recent CD4 count was recorded. Since neuro-biochemical levels are affected by dyslipidemia, diabetes and other derangement of normal physiology, laboratory parameters were obtained for all the participants. These included, complete blood counts, kidney function test, liver function test, fasting lipid profile and a fasting blood glucose level.

\section{Magnetic resonance imaging and spectroscopy}

All MR studies were carried out on a whole body 3 Tesla MRI scanner (Achieva/Ingenia, Phillips Healthcare, The Netherlands). Routine MRI of brain including multi-slice T2-weighted axial images in three orthogonal planes and diffusion-weighted images acquired with a standard head coil. T2-weighted images in three orthogonal planes were used to guide the localization of brain areas, namely, left frontal lobe white matter (FWM) and left basal ganglia (BG) (caudate head nucleus) for acquisition of ${ }^{1} \mathrm{H}$ MR spectra using single voxel MR spectroscopy. In addition, voxel was placed on the CNS lesion in subjects of Group 3. It was also ensured that the selected voxel in the FWM or BG of HIV patients with CNS lesions did not include any lesion or part of it. Single voxel ${ }^{1} \mathrm{H}$ MRS spectra were acquired with a point resolved spectroscopy (PRESS) localization pulse sequence at an echo time (TE) of $35 \mathrm{~ms}$ and a repetition time (TR) of $2000 \mathrm{~ms}$ with 64 or 128 scans. The voxel size used for acquiring the MRS was $16 \mathrm{~mm} \times 16 \mathrm{~mm} \times 16 \mathrm{~mm}$ for the FWM and $12 \mathrm{~mm} \times 12 \mathrm{~mm} \times 12 \mathrm{~mm}$ to $14 \mathrm{~mm} \times$ $14 \mathrm{~mm} \times 14 \mathrm{~mm}$ for the BG depending upon the individual subject's brain anatomy. The absolute concentrations of neuro-biochemicals were estimated using Linear Combination Model software (LC Model, version 6.3-1) which performs deconvolution of spectra by using a basis set of reference spectra [12]. The preprocessing of MR spectra is fully automated by LCModel software including phase, baseline and eddy current correction. Water scaling method using unsuppressed water spectrum acquired from the same voxel used for acquiring water suppressed spectrum. Basis set of spectra (provided by the vendor) for individual neuro-biochemical was used for automatic fitting routine for estimating the absolute concentration and the Cramer-Rao Lower Bounds values for each metabolite. The metabolite concentrations were reported as obtained directly from the LCModel output and were not corrected for T1 and T2 relaxation effects. This method includes correction for $\mathrm{T} 2$ relaxation time and the number of ${ }^{1} \mathrm{H}$ nuclei contributing to the resonance peak. In the ${ }^{1} \mathrm{H}$ MR spectrum obtained, the main resonance peaks identified were arising from tNAA (NAA + N-acetylaspartylglutamate, NAAG) 
at $2.0 \mathrm{ppm}, \mathrm{tCr}(\mathrm{Cr}+$ phosphocreatine, $\mathrm{PCr})$ at $3.0 \mathrm{ppm}$, Cho-containing compounds (tCho) at $3.2 \mathrm{ppm}$, glutamate + glutamine (Glx) at 2.2-2.4 ppm, myoinositol (mI) at $3.5 \mathrm{ppm}$ and lipid/macromolecule (Lip09+MM09) at $0.9 \mathrm{ppm}$. These resonances were analyzed to estimate the concentration (in institutional units) of respective metabolite and the Cramer-Rao lower bounds for all metabolites analyzed in the study were below $15 \%$.

\section{Statistics}

Data was analysed by Stata 12 (Statacorp 4905, Lakeway Drive, College Station, Texas) and described by mean, standard deviation, frequency and percentage. KarlPearson/ Spearman correlation coefficient was used to assess the correlation between two continuous variables. Continuous variables were compared among the Group by one way ANOVA followed by post-hoc comparison with Bonferroni correction. p-value less than 0.05 was considered as significant.

\section{Results}

Demographic profile and clinical features

Mean age among three Groups was not statistically different with the mean age of Group $134.3 \pm 12.5$ years, Group $2,37.0 \pm 13.1$ years and $37.3 \pm 10.6$ years in Group 3. 50 subjects $(70.4 \%)$ were male whereas 21 subjects $(29.6 \%)$ were female, 48 subjects $(67.6 \%)$ were married and 23 subjects $(32.4 \%)$ were unmarried (Table 1$)$.

The mean duration between ART initiation and MRS study for Group 2 is $6.3 \pm 5.9$ months whereas for Group 3 , most of the patients were examined within a month of ART therapy except 3 patients which were studied at 3, 38 and 144 months. However, it is difficult to know the exact time of HIV infection.

Table 1 Comparison of baseline characteristics among three groups

\begin{tabular}{|c|c|c|c|c|}
\hline \multirow[t]{3}{*}{ Variable } & Healthy controls & Asymptomatic HIV & HIV with CNS lesion & Total \\
\hline & Group 1 & Group 2 & Group 3 & \\
\hline & $n=30$ & $n=20$ & $n=21$ & \\
\hline \multicolumn{5}{|l|}{ Gender } \\
\hline Male & 19 & 11 & 20 & $50(70.42 \%)$ \\
\hline Female & 11 & 09 & 01 & $21(29.58 \%)$ \\
\hline \multicolumn{5}{|l|}{ Marital status } \\
\hline Married & 16 & 17 & 15 & $48(67.61 \%)$ \\
\hline Unmarried & 14 & 03 & 06 & $23(32.39 \%)$ \\
\hline \multicolumn{5}{|l|}{ Socioeconomic status } \\
\hline Upper (I) & 17 & 02 & 01 & $20(28.17 \%)$ \\
\hline Upper Middle (II) & 06 & 03 & 02 & $11(15.49 \%)$ \\
\hline Lower Middle (III) & 02 & 05 & 03 & $10(14.08 \%)$ \\
\hline Upper Lower (IV) & 04 & 06 & 15 & $25(35.21 \%)$ \\
\hline Lower (V) & 01 & 04 & 00 & $05(07.04 \%)$ \\
\hline \multicolumn{5}{|l|}{ High risk behavior } \\
\hline None & 30 & 00 & 00 & 30 \\
\hline Not specified & 00 & 04 & 01 & 05 \\
\hline Heterosexual intercourse & 00 & 13 & 18 & 31 \\
\hline I.V. needle sharing & 00 & 00 & 02 & 02 \\
\hline Blood transfusion & 00 & 01 & 00 & 01 \\
\hline Tattooing & 00 & 01 & 00 & 01 \\
\hline From spouse & 00 & 01 & 00 & 01 \\
\hline \multicolumn{5}{|l|}{ Presenting complaints } \\
\hline None & 30 & 00 & 00 & 30 \\
\hline Fever & 00 & 11 & 08 & 19 \\
\hline Altered sensorium & 00 & 00 & 11 & 11 \\
\hline Retrospective after spouse & 00 & 03 & 00 & 03 \\
\hline Antenatal screening & 00 & 02 & 00 & 02 \\
\hline Others & 00 & 04 & 02 & 06 \\
\hline
\end{tabular}


No history of high risk behavior was seen in healthy subjects; heterosexual intercourse was found to be most common mode (31 patients) of HIV transmission in Group 2 and Group 3. Other high risk behaviors include I.V. needle sharing (2 patients), blood transfusion (1 patient), and tattooing (1 patient), from affected spouse ( 1 patient) and in 5 HIV patients no specific etiology could be elicited on the basis of the history. The most common complaint in Group 2 was fever (55\%) followed by other causes (20\%), retrospective diagnosis after spouse $(15 \%)$ followed by during ante natal check-up (10\%). In Group 3, the most common presenting complaint was altered sensorium (52.4\%), followed by fever $(30.1 \%)$ and other causes $(9.5 \%)$ (Table 1) .There was no significant difference in pulse rate and diastolic blood pressure among three Groups studied. Systolic blood pressure was significantly lower in Group 3 compare to Group 1 and respiratory rate was significantly higher in Group 3 compared to Group 1.

\section{Biochemical parameters}

CD4 count was significantly lower ( $p$-value $<0.001)$ in Group 3 (106.95 \pm 86.94 /ul) compared to Group 2 (257.40 \pm 129.09 /ul). Patients of Group 2 and Group 3 were found to have significantly lower levels of hemoglobin ( $p$-value $<0.0001)$, serum calcium ( $p$-value $<0.0001)$, serum sodium levels ( $p$-value $<0.0008)$ and serum albumin levels ( $p$-value $<0.0001$ ) compared to Group 1 (Table 2).

Serum globulin levels were significantly high $(p$ value $<0.0001)$ in Group $2(3 \pm 0.46 \mathrm{~g} / \mathrm{dl})$ and Group 3 $(3.6 \pm 0.98 \mathrm{~g} / \mathrm{dl})$ when compared to Group $1(2.43 \pm 0.59$ $\mathrm{g} / \mathrm{dl})$. Although there was no significant difference in the levels of cholesterol, HDL and triglycerides but LDL level was significantly higher $(p$-value $<0.001)$ in Group 3 $(126.62 \pm 20.9 \mathrm{mg} / \mathrm{dl})$ compared to Group 1 (100.37 \pm $15.33 \mathrm{mg} / \mathrm{dl})$ and Group $2(103.7 \pm 20.9 \mathrm{mg} / \mathrm{dl})$ (Table 2).

\section{MRI and MRS data}

Among 30 healthy controls, 21showed a normal MR imaging and 7 showed non-specific white matter changes. In Group 2, 13 patients showed normal MRI whereas 7 patients showed non-specific white matter changes. Group 3 is a heterogeneous group comprising patients of HIV with tuberculomas (14 patients), progressive multifocal leucoencephalopathy (4 patients), cryptococcal meningitis (2 patients) and 1 patient of suspected intracranial malignancy.

There was no significant difference in the level of tCho in FWM and BG among the three group studied. Patients of Group 3 were found to have significantly lower levels of tNAA in BG ( $p$-value $<0.05)$. Significantly high levels of Glx $(p$-value $<0.05), \mathrm{tCr}(p$-value $<0.05)$ and Lip09 + MM09 ( $p$-value $<0.04)$ were seen in FWM of Group 3. In BG, Glx, tCr and Lip09 + MM09 levels were not significantly different among the three groups studied (Table 3).

Out of 14 HIV patients with CNS tuberculomas, 5 patients $(35.7 \%)$ showed lipid peak while 3 subjects $(21.4 \%)$ showed lactate peak from the lesion. Out of 4 HIV patients with PML, one subject (25\%) showed lipid peak and two (50\%) showed lactate peak from lesion (Fig. 1). No lipid and lactate peak were observed in HIV patient with suspected malignancy and cryptococcal meningitis. We did not find any correlation of laboratory parameters namely, CD4 count, hemoglobin, fasting blood sugar, lipid profile, urea, creatinine or liver enzymes with neuro-biochemical levels.

\section{Discussion}

The immunosuppressed state in HIV patient makes CNS vulnerable to opportunistic infection and tumors as well as susceptible to damage from HIV itself [13]. MRI of brain is a sensitive imaging modality for detection of brain abnormalities in patients infected with HIV, however conventional MRI is not always sensitive for the detection of the early stages of brain HIV infection [14]. No study till date has compared simultaneously healthy controls, asymptomatic HIV patients and HIV patients with CNS involvement by infection or malignancy. We quantified the levels of neuro-biochemical to compare with the results of previous studies.

\section{Clinical evaluation and laboratory findings}

It is expected that during the early stages of HIV infection, there are no neurological abnormality or anatomical changes apparent on MRI. However, it is possible that there may be some molecular and metabolic changes occurring in the brain due to HIV infection. Therefore asymptomatic HIV patients (Group 2) were recruited to investigate whether the HIV infection itself has some impact on brain neuro-biocehmicals even without having overt involvement by infection or malignancy. Majority of the patients of Group 3 were critically ill and were having septicemia because of infection due to underlying immunosuppression and septic shock. Therefore these subjects showed significantly low systolic blood pressure and increased respiratory rate as a component of systemic inflammatory response syndrome (SIRS) [15]. Lower CD4 count is associated with an increased risk of opportunistic infection and increase risk of malignancy. The Swiss HIV Cohort study reported that the risk of developing opportunistic infections is increased by 2.5 if the CD4 count is between $51-200$ cells $/ \mathrm{mm}$; this risk increases to 5.8 for counts $<50$ cells/mm [16]. Various studies have demonstrated that lower CD4 counts are associated with an increased prevalence of opportunistic infections $[17,18]$. This explains the probable presence of 
Table 2 Comparison of laboratory parameters among three groups

\begin{tabular}{|c|c|c|c|c|c|c|c|}
\hline \multirow[t]{4}{*}{ Variable } & \multirow{3}{*}{$\begin{array}{l}\text { Healthy controls } \\
\text { Group } 1\end{array}$} & \multirow{3}{*}{$\begin{array}{l}\text { Asymptomatic HIV } \\
\text { Group } 2\end{array}$} & \multirow[t]{2}{*}{ HIV with CNS lesion } & \multirow[t]{4}{*}{$p$-value } & \multicolumn{3}{|c|}{ Post-hoc comparison } \\
\hline & & & & & | vs || & | vs ||| & \| vs III \\
\hline & & & Group 3 & & & & \\
\hline & $n=30$ & $n=20$ & $n=21$ & & & & \\
\hline Age & $34.33 \pm 12.5$ & $36.95 \pm 13.1$ & $37.29 \pm 10.6$ & 0.63 & & & \\
\hline Respiratory rate Per minute & $15.8 \pm 1.1$ & $15.4 \pm 1.1$ & $16.6 \pm 2.2$ & 0.04 & 1.00 & 0.19 & 0.04 \\
\hline Systolic blood pressure in $\mathrm{mmHg}$ & $121.67 \pm 7.47$ & $118.5 \pm 7.42$ & $112 \pm 12.55$ & 0.002 & 0.72 & 0.001 & 0.08 \\
\hline CD4 count/ul & & $257.40 \pm 129.09$ & $106.95 \pm 86.94$ & 0.0001 & & & \\
\hline Hemoglobin gm/dl & $14.49 \pm 1.57$ & $12.46 \pm 1.28$ & $10.68 \pm 2.69$ & 0.0001 & 0.001 & 0.001 & 0.01 \\
\hline Serum Calcium Meq/L & $9.16 \pm 0.6$ & $8.56 \pm 0.77$ & $8.16 \pm 0.64$ & 0.0001 & 0.007 & 0.001 & 0.18 \\
\hline Serum sodium Meg/L & $140.03 \pm 4.04$ & $138.05 \pm 4.51$ & $134.76 \pm 5.52$ & 0.0008 & 0.43 & 0.001 & 0.72 \\
\hline Serum albumin gm/dl & $4.56 \pm 0.77$ & $3.89 \pm 0.81$ & $3.36 \pm 0.61$ & 0.0001 & 0.008 & 0.001 & 0.72 \\
\hline Serum globulin gm/dl & $2.43 \pm 0.59$ & $3 \pm 0.46$ & $3.6 \pm 0.98$ & 0.0001 & 0.01 & 0.001 & 0.72 \\
\hline LDL mg/dl & $100.37 \pm 15.33$ & $103.7 \pm 20.9$ & $126.62 \pm 20.9$ & 0.0001 & 1 & 0.001 & 0.001 \\
\hline
\end{tabular}

Oneway ANOVA followed by post-hoc comparison with Bonferroni correction 
Table 3 Comparison of concentration of neuro-biochemicals among three groups

\begin{tabular}{|c|c|c|c|c|c|c|c|}
\hline \multirow[t]{4}{*}{ Variable } & \multirow[t]{2}{*}{ Healthy controls } & \multirow[t]{2}{*}{ Asymptomatic HIV } & \multirow[t]{2}{*}{ HIV with CNS lesion } & \multirow[t]{4}{*}{ p-value } & \multicolumn{3}{|c|}{ Post-hoc comparison } \\
\hline & & & & & | vs || & | vs ||| & II vs III \\
\hline & Group 1 & Group 2 & Group 3 & & & & \\
\hline & $\begin{array}{l}n=30 \\
(\mathrm{mmol} / \mathrm{kg})\end{array}$ & $\begin{array}{l}n=20 \\
(\mathrm{mmol} / \mathrm{kg})\end{array}$ & $\begin{array}{l}n=21 \\
(\mathrm{mmol} / \mathrm{kg})\end{array}$ & & & & \\
\hline \multicolumn{8}{|l|}{ tNAA } \\
\hline Frontal & $9.29 \pm 3.11$ & $10.67 \pm 3.8$ & $10.99 \pm 4.11$ & 0.24 & 0.56 & 0.44 & 1 \\
\hline Basal ganglia & $7.31 \pm 0.47$ & $7.29 \pm 0.74$ & $6.71 \pm 0.64$ & 0.01 & 1 & 0.01 & 0.03 \\
\hline \multicolumn{8}{|l|}{ Lip09 + MM09 } \\
\hline FWM & $5.59 \pm 1.56$ & $5.14 \pm 1.79$ & $8.69 \pm 2.96$ & 0.02 & 1 & 0.04 & 0.11 \\
\hline BG & $5.87 \pm 1.05$ & $5.76 \pm 1.95$ & $5.59 \pm 0.53$ & 0.78 & 1 & 1 & 1 \\
\hline \multicolumn{8}{|l|}{ tCho } \\
\hline FWM & $2.08 \pm 0.70$ & $2.50 \pm 0.99$ & $2.62 \pm 0.78$ & 0.07 & 0.26 & 0.12 & 1 \\
\hline BG & $1.62 \pm 0.17$ & $1.68 \pm 0.28$ & $1.56 \pm 0.16$ & 0.27 & 1 & 1 & 0.33 \\
\hline \multicolumn{8}{|l|}{$\mathrm{tCr}$} \\
\hline Frontal & $6.95 \pm 2.56$ & $8.9 \pm 2.9$ & $9.14 \pm 3.04$ & 0.02 & 0.05 & 0.05 & 1 \\
\hline Basal ganglia & $6.95 \pm 1.51$ & $6.3 \pm 1.77$ & $6.62 \pm 0.78$ & 0.19 & 0.4 & 0.38 & 1 \\
\hline \multicolumn{8}{|l|}{ Glx (Glu + Gln) } \\
\hline FWM & $15.0 \pm 6.06$ & $17.08 \pm 5.6$ & $20.4 \pm 7.8$ & 0.05 & 0.82 & 0.05 & 0.47 \\
\hline$B G$ & $13.99 \pm 2.89$ & $14.12 \pm 3.6$ & $13.92 \pm 1.67$ & 0.98 & 1 & 1 & 1 \\
\hline
\end{tabular}

Oneway ANOVA followed by post-hoc comparison with Bonferroni correction

various opportunistic infections like tuberculosis, PML and cryptococcal meningitis in patients of Group 3.

Anemia is a frequent complication that occurs in 20 to $80 \%$ HIV-infected persons and is associated with faster disease progression and mortality [19]. HIV infection may lead to anemia in many ways: changes in cytokine production with subsequent effects on hematopoiesis [20] decreased erythropoietin concentrations [21], opportunistic agents such as Mycobacterium avium complex [22], administration of chemotherapeutic agents such as zidovudine, ganciclovir [23] and cotrimoxazole [24] and myelophthisis caused by cancers such as
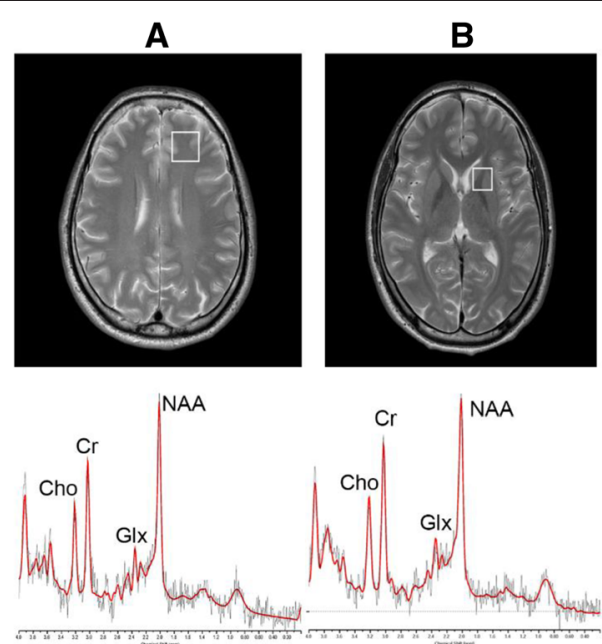
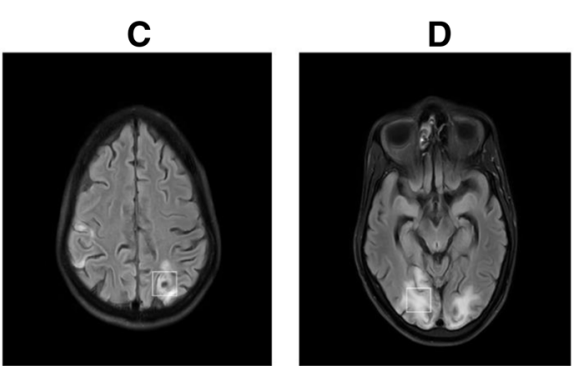

\section{Lipid}

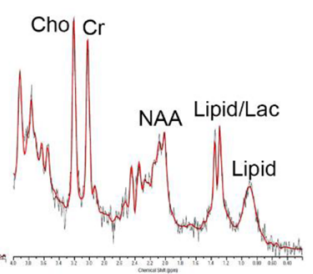

Fig. 1 In vivo ${ }^{1} \mathrm{H}$ MRS spectrum from a left frontal white matter and $\mathbf{b}$ left basal ganglia of a healthy control, $\mathbf{c}$ tuberculoma in an HIV patient and $\mathbf{d}$ white matter lesion from an HIV patient with Progressive Multifocal Leucoencephalopathy. Abbreviations: NAA, N-acetylaspartate; Cho, choline; Cr, creatine;Lac, Lactate; Glx, Glutamate + Glutamine 
lymphosarcoma. Anemia has been associated with progression to AIDS and shorter survival times [25] for HIV-infected patients.

Disturbances of electrolyte metabolism and endocrine regulation like hyponatremia [26, 27], hypo- and hyperkalemia [28, 29] have been observed in HIV patients. Hypocalcaemia, defined by serum calcium level less than $8.5 \mathrm{mg} / \mathrm{dl}$ [30], could be caused by HIV infection [31]. Diarrhea is a common condition seen in HIV and diarrheal diseases could also cause hypocalcaemia through malabsorption and sepsis [32, 33]. It has long been noted that hyponatremia is associated with pulmonary or central nervous system (CNS) infections [34], gastrointestinal sodium losses [35], adrenal insufficiency [36] and renal disorders [37]. Importantly, a CNS or pulmonary infection may result in a syndrome of inappropriate secretion of antidiuretic hormone (SIADH), which plays a pivotal role in the presentation of hyponatremia [35, 38, 39]. Therefore hyponatremia can be correlated with disease progression in HIV.

Serum albumin, is a plasma protein produced by the liver, has a role in many physiologic processes, including vasodilation, endothelial cell apoptosis, and antioxidant reactions [40]. Individuals with conditions such as malnutrition, chronic inflammation, enteropathy, or liver disease can have reduced serum albumin concentrations [40]. Several studies of HIV-infected individuals have determined that hypoalbuminemia is associated with more rapid progression to AIDS and all-cause mortality in developed countries [41, 42]. Globulin levels are also increased in HIV because of coexisting or ongoing chronic inflammatory process.

\section{MRS findings $t N A A$ and $t C r$}

NAA is a neuronal marker and is evenly distributed throughout the cerebral cortex. Although its exact function is not known but it is widely accepted that decreased levels of NAA is a marker for neuronal loss. NAAG is a neuron-specific dipeptide synthesized from NAA and Glu by NAAG synthase, present in brain at its highest concentration [43, 44]. NAAG and its precursor NAA are proven by immune-histo-chemistry to be present within the bodies of neuron [45]. The resonance peak of the methyl group of NAAG at 2.04 ppm strongly overlaps with methyl resonance of NAA in brain MRS. Our findings are in agreement with a previous report [46], which showed decreased tNAA levels in BG but not in FWM of acutely infected HIV patients. BG comprised of neuronal cell bodies and FWM is composed of mainly nerve fibers. The observation of decreased levels of tNAA in BG may indicate significant neuronal loss in this region compared to FWM.
In the present study, a significant increase of $\mathrm{tCr}$ was seen in FWM in Group 3 compared to Groups 1 and 2. This may be due to two possible factors: (i) glial cells contain higher $\mathrm{Cr}$ content than neurons therefore, a cell population change results in change of $\mathrm{Cr}$ level and, (ii) the equilibrium between $\mathrm{PCr}$ and $\mathrm{Cr}$ in creatine kinase reaction may change due to the disease progression [47]. Previous studies have shown changes in $\mathrm{Cr}$ levels in brain of patients with HIV infection. Ernst et al. reported decreased concentration of $\mathrm{Cr}$ in right basal ganglia in patients with HIV and progressive cognitive impairment with motor dysfunction [48]. In a study on ART naïve HIV patients Chang et al. reported an increase in $\mathrm{Cr}$ in frontal white matter and correlation with $\mathrm{CD} 4$ count [49]. These results suggest region specific changes in $\mathrm{Cr}$ metabolism in HIV patients; however, further studies are required to substantiate these findings. Moreover, most of the previous studies analyzed ratios of neuro-biochemicals with respect to $\mathrm{Cr}$, assuming that the concentration of $\mathrm{Cr}$ do not change significantly [5-7, 50, 51]. However, it has been shown that $\mathrm{Cr}$ levels can increase with age and trauma as a hyperosmolar response and some brain pathologies like stroke, tumor, lymphoma, toxoplasmosis are characterized by reduced $\mathrm{Cr}$ [45].

\section{Glutamate and glutamine (Glx)}

Metabolically Glu is stored as glutamine (Gln) in glial cells, and the balanced cycling between these two neurobiochemicals is essential for normal functioning of brain cells. Astrocytes are responsible for uptake of most extracellular Glu via the high-affinity Glu transporters GLT1 and GLAST, and additionally have a vital role in preserving the low extracellular concentration of Glu needed for proper receptor-mediated functions, as well as maintaining low concentrations of extracellular Glu to prevent excite-toxicity [52, 53]. Therefore Gln is an astrocyte marker and Glu is an important neurotransmitter [45]. Glutamate release is subject to calcium regulation, and CD38 is an enzyme in astrocytes involved in intracellular calcium signal. CD38 up-regulation was demonstrated by immune-histo-chemical analysis in brain tissue from HIV encephalopathy (HIVE) patients [54]. Activated astrocytes increase CD38 expression after IL- $1 \beta$ treatment, and this up regulation is mediated by the MAPK and NF-kB signal cascades [55]. Thus the resulting over expression of CD38 partially occurred due to the evoked Glu release, which was in turn caused by elevated $\mathrm{Ca}^{2+}$ influx [56]. However, the role of increased levels of Glu in CSF or plasma as an useful indicator of HIV-associated excite-toxicity remains to be investigated. Experimental evidence suggests that excite-toxicity might play a major role in HIV-induced neuro-degeneration. Ferrase et al. showed increased Glu levels in CSF of HIV patients, compared to healthy subjects, also in patients 
with Alzheimer-type dementia, and patients with other neurologic disorders [9]. Increased glutamate levels in the CSF and plasma of HIV-infected patients and the glutamate levels positively correlated with the degree of dementia and brain atrophy [10]. Nonetheless, it is widely accepted that brain metabolite dysregulation occurs early in HIV infection [57] and persists in the setting of chronic and stable disease [58]. Clinical studies using ${ }^{1} \mathrm{H}$ MRS to evaluate the metabolite levels in early versus chronic cognitively normal HIV+ subjects showed a reduction in the Glx levels of HIV+ subjects compared to controls [57, 59]. It should be noted that Ernst et al. [60] showed no significant increase in white matter Glu levels after adjusting p-value for multiple comparison.

The present study showed increase in Glx in FWM of HIV patients with CNS lesions compared to asymptomatic HIV patients and healthy controls. Metabolism and regulation of Glu and Gln is a complex process in patients with HIV and requires further studies to understand these changes in relation with HIV infection.

\section{Choline and myo-Inositol}

myo-Inositol (mI) is a known glial marker. Many previous studies have shown either an increase in $\mathrm{mI}[6,51]$ or no change in $\mathrm{mI}$ levels $[7,57]$. The present study does not reflect any change in the brain $\mathrm{mI}$ levels. Cho is considered to be a marker of cell membrane and previous studies have reported variable results. While most of the studies showed increased $\mathrm{Cho} / \mathrm{Cr}$ ratio with HIV infection $[5,50]$, few depicted no change in $\mathrm{Cho} / \mathrm{Cr}$ ratio with HIV infection [6, 7]. We did not find any significant changes in choline levels in Group 2 and Group 3 compared to Group 1.

\section{Lipid and macromolecules}

The present study showed significant increase in Lip09/ MM09 signal at $0.9 \mathrm{ppm}$ in FWM in HIV patients with CNS lesion compared to healthy subjects. Over $20 \%$ of the dry weight of brain is lipid and these macromolecules do not appear unless some pathological process liberates the MR visible triglycerides and long chain fatty acids as seen in infection, inflammation, necrosis or stroke [45]. Salvan et al. conducted a study on HIV infected children older than 2 years using ${ }^{1} \mathrm{H}$ MRS to study their cerebral metabolism and to identify metabolic profiles in relation to different stages of the disease. A significant increase of the proportion of the lipid signals ( $p$-value $<0.05)$ was found in all HIV-infected children compare to HIV negative controls. In our study, Group 3 showed increased levels of Lip09/MM09 in FWM compared to healthy controls. In a study by Roc et al., the lipid and lactate/Cr ratio was significantly elevated in HIV positive subjects irrespective of the level of neuro-cognitive impairment on the MRS study of lenticular nuclei [61].

There are some limitations of the present study; the low number of patients in Group 3 which is primarily due to reason that these patients were on life support and with altered sensorium posing a difficulty to subject them to MRS. The number of patients with tuberculomas, PML, cryptococcal meningitis and suspected intracranial malignancy were very low and hence sub-group analysis could not be carried out. Further, it is difficult to conclude with certainty if the neuro-biochemical changes seen were either caused by the varying tissue composition in different MRS voxel or the neurobiochemical change was associated with the cell population change during the diseases progression. In MRS there is possibility of partial volume effect from different tissues, which is difficult to avoid in some anatomical areas with cuboid shaped voxel. In our study, the voxel size and location was adjusted to match the target anatomical area as accurately as possible, however, there is possibility of varying tissue composition being included in the voxel. In addition, comparatively smaller voxel size might have resulted into low signal to noise ratio in some of the spectra obtained. For example, in case of voxel localization in FWM, there is possibility of inclusion of gray matter. We have not acquired the tissue composition data for each voxel to correct for these partial volume effects. In addition, it is difficult to differentiate between lipid and lactate signal at TE of $35 \mathrm{~ms}$.

\section{Conclusion}

The results of the present study showed significant increase in Glx and $\mathrm{tCr}$ in FWM of HIV patients with CNS lesion compared to asymptomatic HIV patients and healthy controls. In BG, there is significant reduction in tNAA. Asymptomatic HIV patients do not have significant alteration in brain neuro-biochemicals compared to healthy controls. Our findings support excitotoxicity effect of increased Glx in HIV associated dementia and region specific metabolic changes in brain associated with HIV infection.

\section{Abbreviations}

AIDS, Acquired immunodeficiency syndrome; ART, anti-retroviral therapy; BG, left basal ganglia caudate head nucleus; CNS, Central nervous system; $\mathrm{Cr}$, Creatine; CSF, cerebrospinal fluid; ELISA, Enzyme linked immune-sorbent assay; FWM, left frontal lobe white matter; GLAST, glutamate astroglial transporter; GLT-1, glutamate transporter type 1; GlX, Glutamate and glutamine; HAND, HIV associated neuro degeneration; HDL, high density lipoprotein; HIV, Human immunodeficiency virus; HIVE, HIV associated encephalopathy; LDL, low density lipoprotein; MAPK, mitogen activated protein kinase; ml, myo-Inositol; MRI, magnetic resonance imaging; MRS, magnetic resonance spectroscopy; NAA, N-acetylaspartate; NAAG, N-acetylaspartylglutamate; NF$\mathrm{kB}$, nuclear factor $-\mathrm{kB}$; PML, progressive multifocal leucoencephalopathy: tCho, Choline and other choline containing compounds 


\section{Acknowledgements}

We thank radiographers from Department of NMR \& MRI Facility for technical support and staff from ART center for helping in recruitment of HIV subjects.

\section{Funding}

No funding was obtained.

\section{Availability of data and materials} Not applicable.

\section{Authors' contributions}

DB participated in patient recruitment, physical examination and detailed neurological examination, acquisition, interpretation of data and writing the manuscript. VK carried out MRI and MRS data acquisition, analysis, interpretation and writing the manuscript. SV participated in acquiring MRI imaging and interpretation. BKD helped in screening of healthy subjects for HIV and estimation of CD4 count in HIV subjects. AKS participated in neurological examination of subjects. RMP performed statistical analysis of data. NRJ participated in interpretation of MRS data and drafting manuscript. SKS helped in recruitment of subjects. SS, NRJ and VK conceived the study, participated in its design and directed its execution. All authors read and approved the final manuscript.

\section{Competing interests}

The authors declare that they have no competing interests.

\section{Consent for publication}

Not applicable.

\section{Ethics approval and consent to participate}

The study has been approved by the Institute Ethics Committee, All India Institute of Medical Sciences, New Delhi. India (IESC/T-11/03.01.2014). Before start of the study, all participants provided written informed consent. Participants are informed that they have the right to discontinue their participation or withdraw from the study at any time.

\section{Author details}

'Department of Medicine, All India Institute of Medical Sciences, Ansari Nagar, New Delhi 110029, India. ${ }^{2}$ Department of NMR \& MRI Facility, All India Institute of Medical Sciences, Ansari Nagar, New Delhi 110029, India. ${ }^{3}$ Department of Radio-diagnosis, All India Institute of Medical Sciences, Ansari Nagar, New Delhi 110029, India. ${ }^{4}$ Department of Microbiology, All India Institute of Medical Sciences, Ansari Nagar, New Delhi 110029, India. ${ }^{5}$ Department of Neurology, All India Institute of Medical Sciences, Ansari Nagar, New Delhi 110029, India. ${ }^{6}$ Department of Biostatistics, All India Institute of Medical Sciences, Ansari Nagar, New Delhi 110029, India.

\section{Received: 20 January 2016 Accepted: 22 June 2016}

Published online: 12 July 2016

\section{References}

1. Global summary of the AIDS epidemic. http://www.who.int/hiv/data/epi core_july2015.png?ua=1. Accessed 9 July 2016.

2. Annual Report. In: Control DoA, editor. New Delhi: Ministry of Health and Family Welfare; 2013-2014. www.mohfw.nic.in/index1.

3. Grant I, Atkinson JH, Hesselink JR, Kennedy CJ, Richman DD, Spector SA, McCutchan JA. Evidence for early central nervous system involvement in the acquired immunodeficiency syndrome (AIDS) and other human immunodeficiency virus (HIV) infections: Studies with neuropsychologic testing and magnetic resonance imaging. Ann Intern Med. 1987;107(6):828-36.

4. Fauci AS, Lane HC. HIV neurology. In Hauser SI and Josephson (Eds.), Harrison's neurology in clinical medicine (2nd ed.). New York: McGraw-Hill; 2010.

5. Chong W, Sweeney B, Wilkinson I, Paley M, Hall-Craggs M, Kendall B, Shepard J, Beecham M, Miller R, Weller I. Proton spectroscopy of the brain in HIV infection: correlation with clinical, immunologic, and MR imaging findings. Radiology. 1993;188(1):119-24.

6. Laubenberger J, Häussinger D, Bayer S, Thielemann S, Schneider B, Mundinger A, Hennig J, Langer M. HIV-related metabolic abnormalities in the brain: depiction with proton MR spectroscopy with short echo times. Radiology. 1996;199(3):805-10.

7. Suwanwelaa N, Phanuphak P, Phanthumchinda K, Suwanwela NC, Tantivatana J, Ruxrungtham K, Suttipan J, Wangsuphachart S, Hanvanich M. Magnetic resonance spectroscopy of the brain in neurologically asymptomatic HIV-infected patients. Magn Reson Imaging. 2000;18(7):859-65.

8. Tarasow E, Wiercińska-Drapało A, Kubas B, Dzienis W, OrzechowskaBobkiewicz A, Prokopowicz D, Walecki J. Cerebral MR spectroscopy in neurologically asymptomatic HIV-infected patients. Acta Radiol. 2003;44(2):206-12.

9. Ferrarese C, Aliprandi A, Tremolizzo L, Stanzani L, De Micheli A, Dolara A, Frattola L. Increased glutamate in CSF and plasma of patients with HIV dementia. Neurology. 2001;57(4):671-5.

10. Bezzi P, Domercq M, Brambilla L, Galli R, Schols D, De Clercq E, Vescovi A, Bagetta G, Kollias G, Meldolesi J, et al. CXCR4-activated astrocyte glutamate release via TNFalpha: amplification by microglia triggers neurotoxicity. Nat Neurosci. 2001;4(7):702-10.

11. Kumar BR, Dudala SR, Rao A. Kuppuswamy's socio-economic status scale-a revision of economic parameter for 2012. Int J Res Dev Health. 2013;1(1):2-4

12. Provencher SW. Automatic quantitation of localized in vivo1H spectra with LCModel. NMR Biomed. 2001;14(4):260-4.

13. Aronow HA, Brew BJ, Price RW. The management of the neurological complications of HIV infection and AIDS. AIDS. 1988;2:S151-160.

14. Post M, Berger J, Duncan R, Quencer R, Pall L, Winfield D. Asymptomatic and neurologically symptomatic HIV-seropositive subjects: results of longterm MR imaging and clinical follow-up. Radiology. 1993;188(3):727-33.

15. Dellinger RP, Levy MM, Carlet JM, Bion J, Parker MM, Jaeschke R, Reinhart K, Angus DC, Brun-Buisson C, Beale R. Surviving Sepsis Campaign: international guidelines for management of severe sepsis and septic shock: 2008. Intensive Care Med. 2008;34(1):17-60.

16. Ledergerber B, Egger $M$, Erard V, Weber R, Hirschel B, Furrer $H$, Battegay M, Vernazza P, Bernasconi E, Opravil M. AIDS-related opportunistic illnesses occurring after initiation of potent antiretroviral therapy: the Swiss HIV Cohort Study. JAMA. 1999;282(23):2220-6.

17. Moore RD, Chaisson RE. Natural history of opportunistic disease in an HIVinfected urban clinical cohort. Ann Intern Med. 1996;124(7):633-42.

18. Agarwal D, Chakravarty J, Sundar S, Gupta V, Bhatia B. Correlation between clinical features and degree of immunosuppression in HIV infected children. Indian Pediatr. 2008:45(2):140.

19. Belperio PS, Rhew DC. Prevalence and outcomes of anemia in individuals with human immunodeficiency virus: a systematic review of the literature. Am J Med. 2004;116(7):27-43.

20. Maciejewski JP, Weichold FF, Young NS. HIV-1 suppression of hematopoiesis in vitro mediated by envelope glycoprotein and TNF-alpha. J Immunol. 1994;153(9):4303-10

21. Spivak JL, Barnes DC, Fuchs E, Quinn TC. Serum immunoreactive erythropoietin in HIV-infected patients. JAMA. 1989;261(21):3104-7.

22. Desforges JF, Horsburgh Jr CR. Mycobacterium avium complex infection in the acquired immunodeficiency syndrome. N Engl J Med. 1991:324(19):1332-8.

23. Faulds D, Heel RC. Ganciclovir: A review of its antiviral activity,pharmacokinetic properties and therapeutic efficiency in cytomegalovirus infections. Drugs 1990;39(4):597-638.

24. Keisu M, Wiholm B, Palmblad J. Trimethoprim-sulphamethoxazole-associated blood dyscrasias. Ten years' experience of the Swedish spontaneous reporting system. J Intern Med. 1990;228(4):353-60.

25. Morfeldt-månson L, Böttiger B, Nilsson B, Stedingk L-V. Clinical signs and laboratory markers in predicting progression to AIDS in HIV-1 infected patients. Scand J Infect Dis. 1991;23(4):443-9.

26. Glassock RJ, Cohen AH, Danovitch G, Parsa KP. Human immunodeficiency virus (HIV) infection and the kidney. Ann Intern Med 1990;112:35-49.

27. Vitting KE, Gardenswartz MH, Zabetakis PM, Tapper ML, Gleim GW, Agrawal M, Michelis MF. Frequency of hyponatremia and nonosmolar vasopressin release in the acquired immunodeficiency syndrome. JAMA. 1990;263(7):973-8.

28. Guy R, Turberg Y, Davidson R, Finnerty G, MacGregor G, Wise P. Mineralocorticoid deficiency in HIV infection. BMJ. 1989;298(6672):496-7.

29. Velazquez H, Perazella MA, Wright FS, Ellison DH. Renal mechanism of trimethoprim-induced hyperkalemia. Ann Intern Med. 1993;119(4):296-301.

30. Ross AC, Taylor CL, Yaktine AL, Del Valle HB, eds. Dietary reference intakes for calcium and vitamin D. National Academies Press; 2011. 
31. Emejulu A, Onwuliri V, Ojiako O. Electrolyte Abnormalities and Renal Impairment in Asymptomatic HIV-infected Patients in Owerri, South Eastern Nigeria. Aust J Basic Appl Sci. 2011;5(3):257-60.

32. Strauss KW. Endocrine complications of the acquired immunodeficiency syndrome. Arch Intern Med. 1991;151(7):1441-4.

33. Peter SA. Disorders of serum calcium in acquired immunodeficiency syndrome. J Natl Med Assoc. 1992;84(7):626.

34. Zilberberg MD, Exuzides A, Spalding J, Foreman A, Jones AG, Colby C, Shorr AF. Hyponatremia and hospital outcomes among patients with pneumonia: a retrospective cohort study. BMC Pulm Med. 2008;8(1):16.

35. Tang WW, Kaptein EM, Feinstein El, Massry SG. Hyponatremia in hospitalized patients with the acquired immunodeficiency syndrome (AIDS) and the AIDS-related complex. Am J Med. 1993;94(2):169-74.

36. Uno K, Konishi M, Yoshimoto E, Kasahara K, Mori K, Maeda K, Ishida E, Konishi N, Murakawa K, Mikasa K. Fatal cytomegalovirus-associated adrenal insufficiency in an AIDS patient receiving corticosteroid therapy. Intern Med. 2007:46(9):617-20.

37. Berggren R, Batuman V. HIV-associated renal disorders: recent insights into pathogenesis and treatment. Curr HIV/AIDS Rep. 2005;2(3):109-15.

38. Nettles R. Hyponatremia in a Patient With AIDS. Infect Dis Clin Pract. 2002;11(6):361-4

39. Palmer BF. Hyponatremia in patients with central nervous system disease: SIADH versus CSW. Trends Endocrinol Metabolism. 2003;14(4):182-7.

40. Don BR, Kaysen G. Serum albumin: relationship to inflammation and nutrition. Semin Dial. 2004;17(6):432-7.

41. Shah S, Smith CJ, Lampe F, Youle M, Johnson MA, Phillips AN, Sabin CA. Haemoglobin and albumin as markers of HIV disease progression in the highly active antiretrovial therapy era: relationships with gender. HIV Med. 2007;8(1):38-45

42. Mehta SH, Astemborski J, Sterling TR, Thomas DL, Vlahov D. Serum albumin as a prognostic indicator for HIV disease progression. AIDS Res Human Retroviruses. 2006;22(1):14-21.

43. Baslow MH. An answer to"The Nagging Question of the Function of NAcetylaspartylglutamate". Neurosci Commun. 2015;2:e844.

44. Moffett JR, Ross B, Arun P, Madhavarao CN, Namboodiri AM. NAcetylaspartate in the CNS: from neurodiagnostics to neurobiology. Prog Neurobiol. 2007;81(2):89-131

45. Danielsen ER, Ross B. Magnetic Resonance Spectroscopy Diagnosis of Neurological Disease. New York: Marcel Dekker; 1999.

46. Lentz MR, Kim W-K, Kim H, Soulas C, Lee V, Venna N, Halpern EF, Rosenberg ES, Williams K, Gonzalez R. Alterations in brain metabolism during the first year of HIV infection. J Neurovirol. 2011;17(3):220-9.

47. Urenjak J, Williams SR, Gadian DG, Noble M. Proton nuclear magnetic resonance spectroscopy unambiguously identifies different neural cell types. J Neurosci. 1993;13(3):981-9.

48. Ernst $\mathrm{T}$, Itti $\mathrm{E}$, Itti L, Chang L. Changes in cerebral metabolism are detected prior to perfusion changes in early HIV-CMC: A coregistered $1 \mathrm{H}$ MRS and SPECT study. J Magn Reson Imaging. 2000;12(6):859-65.

49. Chang $L$, Ernst T, Witt MD, Ames N, Gaiefsky M, Miller E. Relationships among brain metabolites, cognitive function, and viral loads in antiretroviral-naıve HIV patients. Neuroimage. 2002;17(3):1638-48.

50. Simone I, Federico F, Tortorella C, Andreula C, Zimatore G, Giannini P, Angarano G, Lucivero V, Picciola P, Carrara D. Localised 1H-MR spectroscopy for metabolic characterisation of diffuse and focal brain lesions in patients infected with HIV. J Neurol Neurosurg Psychiatry. 1998;64(4):516-23.

51. Salvan A-M, Lamoureux S, Michel G, Confort-Gouny S, Cozzone PJ, VionDury J. Localized proton magnetic resonance spectroscopy of the brain in children infected with human immunodeficiency virus with and without encephalopathy. Pediatr Res. 1998:44(5):755-62.

52. Schousboe A. Role of astrocytes in the maintenance and modulation of glutamatergic and GABAergic neurotransmission. Neurochem Res. 2003; 28(2):347-52.

53. Schousboe A, Waagepetersen HS. Role of astrocytes in glutamate homeostasis: implications for excitotoxicity. Neurotox Res. 2005;8(3-4):221-5.

54. Kou W, Banerjee S, Eudy J, Smith LM, Persidsky R, Borgmann K, Wu L, Sakhuja N, Deshpande MS, Walseth TF, et al. CD38 regulation in activated astrocytes: implications for neuroinflammation and HIV-1 brain infection. $J$ Neurosci Res. 2009;87(10):2326-39.

55. Mamik MK, Banerjee S, Walseth TF, Hirte R, Tang L, Borgmann K, Ghorpade A. HIV-1 and IL-1 $\beta$ regulate astrocytic CD38 through mitogen-activated protein kinases and nuclear factor-kB signaling mechanisms. Neuroinflammation. 2011:25(8):145.

56. Bruzzone S, Verderio C, Schenk U, Fedele E, Zocchi E, Matteoli M, De Flora A. Glutamate-mediated overexpression of CD38 in astrocytes cultured with neurones. J Neurochem. 2004;89(1):264-72.

57. Sailasuta N, Ross W, Ananworanich J, Chalermchai T, DeGruttola V, Lerdlum S, Pothisri M, Busovaca E, Ratto-Kim S, Jagodzinski L. Change in brain magnetic resonance spectroscopy after treatment during acute HIV infection. PLoS One. 2012;7(11):e49272.

58. Harezlak J, Buchthal S, Taylor M, Schifitto G, Zhong J, Daar E, Alger J, Singer E, Campbell T, Yiannoutsos C, et al. Persistence of HIV-associated cognitive impairment, inflammation, and neuronal injury in era of highly active antiretroviral treatment. AIDS. 2011;25(5):625-33.

59. Lentz M, Kim W, Lee V, Bazner S, Halpern E, Venna N, Williams K, Rosenberg E, Gonzalez R. Changes in MRS neuronal markers and T cell phenotypes observed during early HIV infection. Neurology. 2009;72(17):1465-72.

60. Ernst T, Jiang CS, Nakama H, Buchthal S, Chang L. Lower brain glutamate is associated with cognitive deficits in HIV patients: A new mechanism for HIV-associated neurocognitive disorder. J Magn Reson Imaging. 2010;32(5):1045-53.

61. Roc AC, Ances BM, Chawla S, Korczykowski M, Wolf RL, Kolson DL, Detre JA, Poptani $\mathrm{H}$. Detection of human immunodeficiency virus-induced inflammation and oxidative stress in lenticular nuclei with magnetic resonance spectroscopy despite antiretroviral therapy. Arch Neurol. 2007:64(9):1249-57.

\section{Submit your next manuscript to BioMed Central and we will help you at every step:}

- We accept pre-submission inquiries

- Our selector tool helps you to find the most relevant journal

- We provide round the clock customer support

- Convenient online submission

- Thorough peer review

- Inclusion in PubMed and all major indexing services

- Maximum visibility for your research

Submit your manuscript at www.biomedcentral.com/submit 